\title{
ПРИМЕНЕНИЕ МЕТОДА ПОЛИНОМИАЛЬНОЙ АППРОКСИМАЦИИ ДЛЯ ВЫДЕЛЕНИЯ ТЕНДЕНЦИЙ СКОРОСТИ РОСТА ТОРФЯНОЙ ЗАЛЕЖИ НА ПРИМЕРЕ БОЛОТА НИГУЛА
}

Для обработки вертикальной серии радиоуглеродных датировок предлагается применять метод полиномиальной аппроксимации. Дается интерпретация результатов сопоставления кривых скорости роста залежи на верховом болоте Нигула и уровня воды в Балтийском море в голоцене.

Исследованием скорости роста торфяных залежей на территории Әстонии занимались многие авторы (Thomson, 1929; Вебер, 1967; Valk, 1969; Ильвес, 1970; Илометс, 1980, 1981 и др.), но в их выводах наблюдаются некоторые разногласия. Можно перечислить несколько причин расхождений результатов: 1) частое отличие продолжительности фаз развития голоценовых лесов и климатических периодов от принятой в настоящее время (рис. 1), 2) использование в последнее время дендрохронологически исправленных радиоуглеродных данных, 3) различные методы исследования и разные типы изучаемых болот.

Основная трудность решения поставленной задачи заключается в высокой вариабельности скорости накопления торфа, когда многие переменные ведут себя как случайные компоненты. Это обстоятельство затрудняет анализ исходных данных. Поэтому мы предлагаем неизвестную функцию роста залежи во времени аппроксимировать алгебраическими полиномами, что позволит выделить общие тенденции в скорости аккумуляции торфа от непредставительных флуктуаций. Изоляция строго детерминированной тенденции от случайной составляющей и составляющей погрешностей облегчает выяснение исходных причин изменения скорости накопления торфа.

Пусть $V_{t}$ - скорость роста залежи в момент $t$, тогда можно записать формулу

$$
V_{t}=U_{t}+\varepsilon_{t},
$$

где $U_{t}$ - трендовый компонент скорости роста залежи в момент $t$, $\varepsilon_{t}$ - остаточный компонент скорости роста залежи в момент $t$ (сюда входит и случайная погрешность эксперимента).

Рис. 1. Продолжительность климатнческих пернодов (годы): I по местной стратиграфической схеме Эстонской ССР (Каяк и др., 1976), II - по У. Валку (Valk, 1974), III - по K. Ю. Beберу (1967).

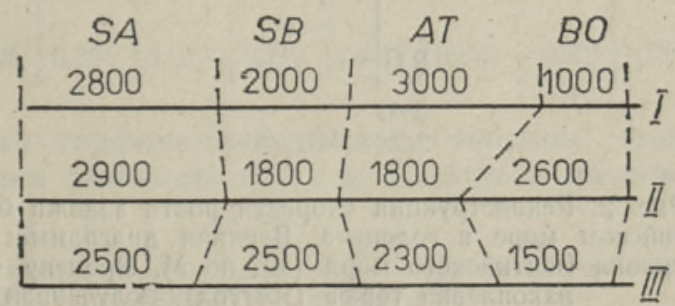


Методика вычисления трендовой составляющей скорости накопления торфа применительно к озерным отложениям изложена в монографии Г. Дигерфельдта (Digerfeldt, 1972). Соответственно предложенной методике следует построить полином необходимого порядка

$$
t=b_{0}+b_{1} d+\ldots+b_{j} d^{j}+\ldots+b_{p} d^{p},
$$

где $t$ - время (годы), $d$ - глубина залежи (м), $b_{0}, \ldots, b_{p}$ - параметры полинома.

Производная полинома (1)

$$
t^{\prime}=b_{1}+2 b_{2} d+\ldots+j b_{j} d^{j-1}+\ldots+p b_{p} d^{p-1}
$$

дает увеличение времени (год/м). Для получения кривой скорости накопления торфа (мм/год) необходимо было вычислить $1 / t^{\prime}$, т. е. обратное значение полинома (2) и умножить его на 1000.

Болото Нигула, для которого мы провели расчеты скорости торфонакопления, расположено на водораздельном участке западного края Сакалаского плато, т.е. в районе крупных верховых болот ЮгоЗападной Эстонии. Площадь его 2960 га, длина 9,5 и ширина 3,5 км. Болото вытянуто с северо-северо-востока на юго-юго-запад, что предопределяется ориентацией расположенных здесь мелких друмлинов. На болоте преобладают грядово-мочажинный и грядово-озерковый комплексы с редкой карликовой сосной. Доминирует верховая залежь (Пиррус, 1963).

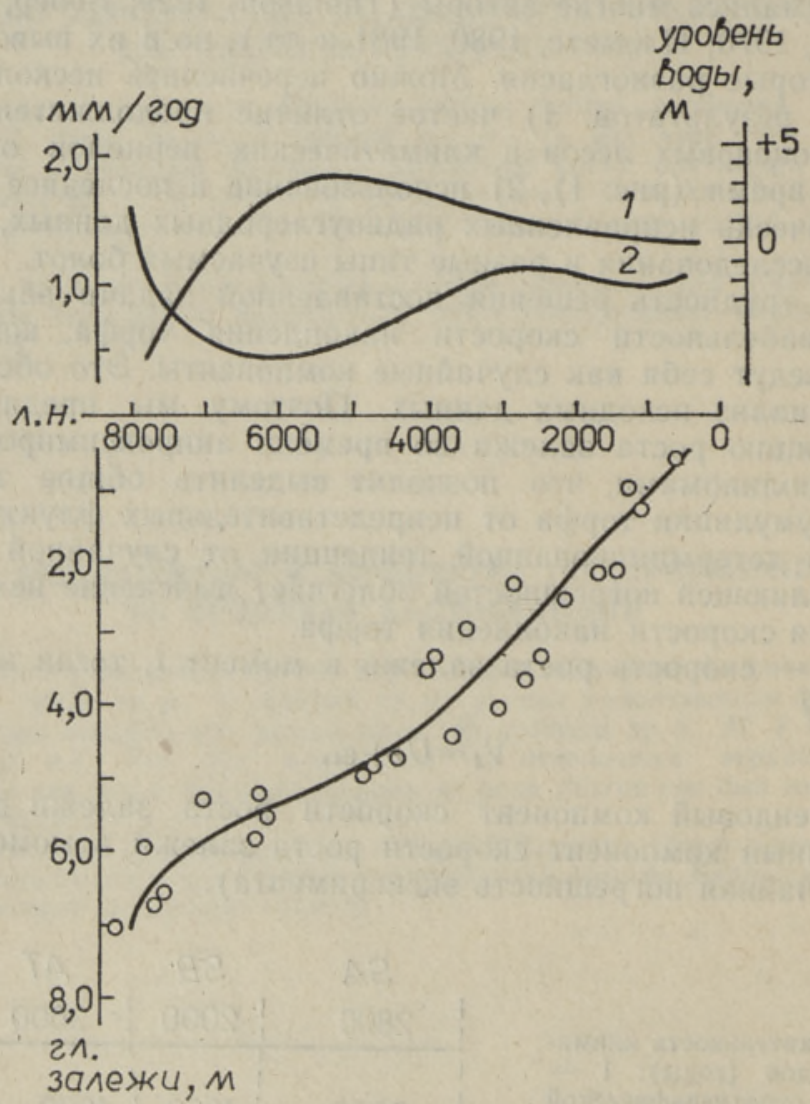

Рнс. 2. Реконструкция скорости роста залежи болота Нигула и уровня воды в Балтийском море в голоцене. Верхняя диаграмма: 1 - плавная эвстатическая кривая уровня Балтийского моря (м), по M. Эронену (Eronen, 1974), 2 - кривая скорости накоплення торфа (мм/год), полученная по полиному пятого порядка. 
Исходными данными с целью построения модели служила вертикальная серия радиоуглеродных датировок двух опорных разрезов (Нигула I, Нигула II). Эти данные опубликованы в статье А. Сарв и Э. Ильвеса (1976). Для этих разрезов имеются 24 определения радиоуглеродного возраста торфяных отложений (рис. 2, нижняя диаграмма). Разрезы расположены на западном и восточном участках болотного массива в местах мощной залежи верхового типа.

В разрезе Нигула I торфяные отложения подстилаются слоем сапропеля толщиной 0,2 м. Залежь сложена в основании на глубине от 5,1 до 5,7 м (6000-7700 л. н.) низинным тростниковым и осоковым торфом, на глубине от 4,5 до 5,1 м (4200-6000 л. н.) переходным пушицевым и травянисто-древесным, а сверху перекрыта верховзіми видами торфа. В составе последних преобладают фускум- и комплексный торф иногда с прослоями пушицево-сфагнового.

В разрезе Нигула II в качестве донных отложений наблюдается также слой сапропеля толщиной 0,2 м. Сапропель на глубине 6,8 м (7300 л.н.) перекрыт низинным осоковым и осоково-сфагновым видами торфа. Непосредственно на низинных торфах залегают верховые. В интервале $3,1-6,0$ м (2400-6400 л. н.) залежь представлена пушицево-сфагновым торфом с прослойками пушицевого и фускумторфов. Выше наблюдается фускум-торф.

Имея отмеченные выше датировки возраста, нам необходимо было построить модель такого порядка, по которой можно было бы дать генетическую интерпретацию изменения процесса накопления торфа на болоте. Модель, которая при аппроксимации незначительно увеличивает корреляцию, теоретически мало отличается от предыдущей (Крамбейн, Грейбилл, 1969; Аронов, 1977; Девис, 1977). Поэтому нет смысла строить полиномы высших порядков, а нужно проследить за увеличением корреляции. Для вычисления оптимальной модели мы составили таблицу, в которой привели значения увеличения корреляции при усложнении модели. Из таблицы видно, что начиная с пятого порядка дополнительная доля корреляции увеличивается очень мало. Глазомерное прослеживание наиболее устойчивых тенденций, проявляющихся на графиках, подтвердило выбор модели пятого порядка (рис. 2, нижняя диаграмма).

Вычисления, проведенные по полиному пятого порядка в соответствии с вышеописанной методикой, дали изображенную на рис. 2 (верхняя диаграмма) кривую скорости накопления торфа болота Нигула. Кривая показывает самый медленный прирост торфа 7000-5000 лет назад,* что соответствует атлантическому климатическому периоду.

Зависимость коэффициента корреляции от порядка модели

\begin{tabular}{l|r|r|r|r|r|r|r|r|r|r}
\hline & \multicolumn{7}{|c}{ Порядок модели } \\
\cline { 2 - 8 } & 1 & 2 & 3 & 4 & 5 & 6 & 7 & 8 & 9 & 10 \\
\hline $\begin{array}{c}\text { Коэффнциент } \\
\text { корреляция } \\
\begin{array}{c}\text { Дополнительная } \\
\text { доля корреляции }\end{array}\end{array}$ & 0,300 & 0,529 & 0,534 & 0,585 & 0,602 & 0,603 & 0,606 & 0,613 & 0,615 & 0,619 \\
& 0,229 & 0,005 & 0,051 & 0,017 & 0,001 & 0,003 & 0,007 & 0,002 & 0,004
\end{tabular}

Как известно, интенсивность торфонакопления в основном предопределяется водно-минеральным режимом питания болотного массива.

* Для более наглядного сопоставления данных с результатами других исследований мы не применяли дендрохронологическую поправку $\mathrm{k}{ }^{14} \mathrm{C}$-датировкам. 
Режим питания, в свою очередь, создается совокупностью различных факторов - гидрогеологических, геоморфологических, климатических и других. Согласно представлениям о водном режиме болот и диаграмме (рис. 2) для болота Нигула можно отметить, что во время первой половины атлантического климатического периода уменьшалось соотношение между поступлением воды и испарением, что вызывало тенденцию замедления скорости накопления торфа. Противоположная тенденция торфонакопления началась во второй половине атлантического периода главным образом, вероятно, в силу уменьшения температуры. Тут необходимо отметить, что плавное изменение скорости осадконакопления на графике (рис. 2) не указывает на относительное постоянство климата в голоцене. Наоборот, чрезвычайно сложная изменчивость скорости роста залежи свидетельствует, что в течение изучаемого нами периода происходили многократные колебания водного режима болот (Ilves, 1969). В данном случае мы изучаем компонент изменчивости, который детерминирован общими климатическими причинами. Другая, с точки зрения нашего задания, непредставительная часть входит в остаточную составляющую.

Мы имеем возможность проверить, отражает ли наша модель реальные природные условия. Известным способом восстановления климатов прошлого является изучение изменчивости уровня древних водоемов. Повышение уровня воды Мирового океана объясняется главным образом уменьшением количества льда на земном шаре в результате всеобщего потепления климата. Это повышение должно сказаться также на уровнях внутренних морей, в том числе Балтийского моря во время литориновой стадии. Исследование геологии берегов Литоринового моря позволило к настоящему времени выделить не одну, а ряд трансгрессий, при сопоставлении и интерпретации которых возникли определенные трудности (Гринбергс и др., 1975; Кессел, Пуннинг, 1976 и др.).

В последнее время в результате обобщения богатого фактического материала предыдущих исследований разработаны новые положения, по которым имеющиеся разногласия находят довольно достоверное объяснение (Eronen, 1974; Пуннинг, 1982). В этих работах оцениваются эвстатические движения уровней Балтийского бассейна в целом, исходя из положения, что изостатическое поднятие Фенноскандии в голоцене было непрерывным и равномерным процессом. При этом в результате раздробления земной коры на отдельные блоки и вследствие перемещения центра поднятия допускаются местные неравномерности.

M. Эронен сконструировал плавную эвстатическую кривую уровня Балтийского бассейна, учитывая вертикальные движения земной коры и перемещения древних береговых линий моря (рис. 2). Характер кривой показывает, что начало атлантического климатического оптимума сопровождалось быстрым повышением уровня воды в Балтийском море, и около 4000-6000 лет назад уровень воды достигал максимальной высоты: на 3-4 м выше современного (Eronen, 1974). Начало климатического оптимума соответствует первой литориновой трансгрессии, выделенной многими исследователями (Кессел, Раукас, 1967; Кессел, Пуннинг, 1969; Гринбергс, 1957; Mörner, 1969; Donner, 1964; Eronen, 1974, Glückert, 1976 и др.). В это время повышение уровня воды по отношению к изостатическому поднятию было наиболее быстрым на юге Балтики, где земная кора поднималась незначительно, а местами даже опускалась, вследствие чего морские воды затопили здесь обширные низменные участки побережья.

М. Әронен, исследуя изостазию и эвстазию, показал, что в течение литориновой стадии в Балтийском бассейне была только одна единая трансгрессия, и появление этой трансгрессии в различных частях Бал- 
тики в разное время - следствие локальных неравномерностей в процессе неотектонического поднятия земной коры, а многократные колебания уровня воды настолько слабы, что их амплитуда даже не выходит за пределы погрешностей методов исследования.

Приведенный нами показатель скорости накопления торфа в природных условиях болота Нигула непосредственно не зависит от уровня воды в Балтийском море и поэтому его можно учитывать при климатических реконструкциях. Выделенный трендовый компонент скорости торфонакопления показывает, что во время атлантического климатического периода, когда эвстатическое поднятие в Мировом океане и в связанном с ним Балтийском бассейне достигло максимальной высоты, с незначительным опережением уменьшалась обводненность верхового болота Нигула (рис. 2).

Наш результат подтверждает гипотезу И. Троэлс-Смита (TroelsSmith, 1956), по которой литориновой трансгрессии должно соответствовать уменьшение обводненности болот и озер в районе Балтикщ Предпосылкой этому служит теплый климат и увеличение испарения по отношению к осадкам. В случае потепления климата уменьшается количество льда на Земном шаре и повышается уровень воды в Мировом океане и в связанных с ним морях, а повышение температуры (испарения) по отношению к осадкам приводит к уменьшению увлажненности болот. В основном в результате экологической интерпретации развития растительности И. Троэлс-Смит приходит к выводу, что именно такие условия могли господствовать в районе Балтики во время морских трансгрессий. К сожалению, имеющиеся данные по стратиграфии болот и озер Скандинавии до сих пор не позволяют принять или отвергнуть его гипотезу. С гипотезой Й. Троэлс-Смита согласуются только обобщающий вывод Б. Берглунда (Berglund, 1983), что ускоренная аккумуляция торфа позднее чем 5000 лет назад в Южной Скандинавии, по-видимому, совпадает с повышением уровня воды в озерах, и результаты изучения озерных отложений в болоте Аамосен (Дания) (Jørgensen, 1963).

Исследования советских ученых не опровергают основную идею И. Троэлс-Смита. В монографии Н. А. Хотинского (1977) сопоставлены схемы изменения теплообеспеченности и увлажненности в голоцене. Ход кривых на этих схемах свидетельствует, что кульминация температуры в мировом масштабе и кульминация тепла по отношению к осадкам в районе Балтики соответствуют именно атлантическому климатическому периоду. Позже этого периода названное отношение постепенно изменяется в пользу увлажненности (Хотинский, 1977, рис. 49 $I$ и 52). Таким образом, наше заключение о возможности существования теплого и относительно континентального климата в ЮгоЗападной Эстонии в атлантическое время приводит к поддержке представления Н. А. Хотинского.

В последнее время для обработки спорово-пыльцевых данных применяются математические методы. Количественные климатические данные (Бурашникова и др., 1982), полученные с привлечением метода аналогии на основании палинологических данных, показывают, что во время климатического оптимума голоцена (5000-6000 л. н.) Эстония находилась в более континентальных условиях, чем в настоящее время. В. А. Климанов (1982) построил модели температур января и июля для климатического оптимума с применением информационного анализа. Их сопоставление показывает, что в районе Прибалтики годовые амплитуды температур были немного выше современных, что также не опровергает выдвинутую гипотезу.

Скорость роста торфяных залежей и колебания уровня Балтийского бассейна, несомненно, имеют общую причинную связь с климатом. Но 
эта связь сложная. Необходимо не забывать, что наша кривая скорости роста залежи будет уточняться по мере поступления новых сведений о возрасте торфяных отложений, а также о роли различных факторов (уплотнение залежи в зависимости от мощности, свойств и ботанического состава, ошибки радиоуглеродного датирования, биопродукция растительных сообществ, автономные процессы болотных экосистем и др.), влияющих на характер кривой. Аналогичные кривые, построенные в дальнейшем для других болотных массивов Эстонии, будут также различаться в зависимости от особенностей гидрогеологогеоморфологических условий водно-минерального питания конкретного исследуемого массива. Но все же при предположении, что гипотеза И. Троэлс-Смита верна и для Эстонии, в подобных кривых должна содержаться информация об увеличении континентальности в основном в первой половине атлантического климатического периода.

\section{ЛИТЕРАТ УРА}

Аронов В. И. Методы математической обработки геологических данных на ЭВМ. M., 1977 .

Бурашникова Т. А., Муратова М. В., Суетова И. А. Климатическая модель территории Советского Союза во время голоценового оптимума. - В кн.: Развитие природы территории СССР в позднем плейстоцене и голоцене. М., 1982, $245-251$.

Вебер К. Ю. Возраст болот и прирост торфа по данным спорово-пыльцевых диаграмм Северо-Восточной Эстония. - В кн.: Природа болот и методы их исследований. Л., 1967, 103-107.

Гринберас Э. Ф. Позднеледниковая и послеледниковая история побережья Латвийской ССР. Рнга, 1957.

Гринберас Э. Ф., Кессел Х. Я., Пуннине Я.-М., Раямяэ Р. М. Применение радиоуглеродного метода для изучения древнебалтийских трансгрессий в Латвии. В кн.: Состояние методических исследований в области абсолютной геохронологин. М., 1975, $182-186$.

Девис Дж. С. Статистика и анализ геологических данных. М., 1977.

Илометс М. А. Связь между скоростью аккумуляции торфа и первичной продуктивностью болота в юго-западной Эстонии. - Бот. ж., 1980, 65, 1337-1344.

Илометс М. А. Изучение динамики прироста сфагнума и сфагнового торфа в целях стратиграфического расчленения торфяных залежей. Автореф. канд. дис. Таллин, 1981.

Ильвес Э. О. О колебаниях климата голоцена в свете радиометрических $\left({ }^{14} \mathrm{C}\right)$ данных. - В кн.: Пернодизация и геохронология плейстоцена. Л., 1970, 96-99.

Каяк К., Кессел Х., Лийвранд Э., Пиррус Р., Раукас А., Сарв А. Стратиграфия четвертичных отложений Эстонин. - В кн.: Стратиграфия четвертичных отложений Прибалтнки. Вильнюс, 1976, 4-52.

Кессел Х., Пуннина Я.-М. О возрасте максимальной литориновой трансгрессии в Ленинградской области. - Изв. АН ЭССР. Хим. Геол., 1976, 25, 222-229.

Кессел Х., Пуннина Я.-М. Об абсолютном возрасте голоценовых трансгрессий Балтики на террнтории Эстонин. - Изв. АН ЭССР. Хим. Геол., 1969, 18, $140-153$.

Keсceл X., Раукас А. Прибрежные отложения Анцилового озера и Литоринового моря в Эстонин. Таллин, 1967.

Климанов В. А. Климат Восточной Европы в климатическом оптимуме голоцена (по данным палинологии). - В кн.: Развитие прнроды территорни СССР в позднем плейстоцене и голоцене. М., 1982, 251-258.

Крамбейн У., Грейбилл Ф. Статистические модели в геологин. М., 1969, 251-282.

Пиррус $Р$. O. История развития верхового болота Нигула. - Тр. Ин-та геол. АН ЭССР, 1963, 12, 163-173.

Пуннине Я.-М. Эвстатические колебания уровня Балтики в голоцене. - В кн.: Колебания уровня морей и океанов за 15000 лет. М., 1982, 134-143.

Сарв А., Ильвес Э. Стратиграфия и геохронология голоценовых озерных и болотных отложеннй юго-западной части Эстонии. - В кн.: Палннология в континентальных и морских геологических исследованиях. Рнга, 1976, 47-59.

Хотинский Н. А. Голоцен Северной Евразин. М., 1977. 
Berglund, B. E. Palaeoclimatic changes in Scandinavia and on greenland - a tentative correlation based on lake and bog stratigraphical studies. - Quaternary Studies in Poland, 1983, 4, 27-44.

Digerfeldt, $G$. The post-glacial development of Lake Trummen. - Folia limnologica scandinavica, 1972, 16, 5-104.

Donner, J. J. The late-glacial and post-glacial emergence of southwestern Finland. Soc. Sci. Fennica Comment. Physico-Math., 1964, 30, 5, 5-47.

Eronen, M. The history of the Littorina Sea and associated Holocene events. - Soc. Sci. Fennica Comment. Physico-Math., 1974, 44, 4, 79-195.

Glückert, G. Post-glacial shore-level displacement of the Baltic in SW Finland. Ann. Acad. sci. fennicae, 1976, ser. A, 5-92.

Ilves, E. Kuidas muutus kliima. - Eesti Loodus, 1969, 7, 402-403.

Jorgensen, S. Early post-glacial in Aamosen I. - Danmarks geol. undersøgelse, 1963, $87,5-79$.

Mörner, N. A. The Late Quaternary history of the Kattegat Sea and the Swedish west coast. - Sver. geol. unders., 1969, ser. C, 640, 5-487.

Thomson, P. Die regionale Entwicklungsgeschichte der Wälder Estlands. - Acta et Comment. Univ. Tartuensis, 1929, A17, 2, 3-88.

Troels-Smith, J. Vandstandssvingninger $\mathrm{i}$ indsobassiner og havtransgressioner og -regressioner. Medd. Dansk geol. fören, 1956, 13, 127-128.

Valk, $U$. Eesti soode vanusest ja turba juurdekasvu kiirusest holotseeni vältel. - Rmt.: Metsanduslikud uurimused VII. Tallinn, 1969, 80-117.

Valk, U. Eesti metsade arenemislugu. - Rmt.: Eesti metsad. Tallinn, 1974, 31-40.

Ннститут геологии

Академии наук Эстонской ССР
Поступнла в редакцию

15/VI 1984

\section{K. ORGLA}

\section{POLUNOMIAALSE LÄHENDAMISE MEETODI KASUTAMISEST TURBALASUNDI KASVUKIIRUSE TENDENTSIDE KINDLAKSTEGEMISEKS NIGULA RABA NÄITEL}

Turbalasundi kasvukiiruse määramiseks vertikaalse seeria radioaktiivse süsiniku dateeringute järgi soovitatakse kasutada polünomiaalse lähendamise meetodit. Meetodi rakenduse näitena on toodud Nigula raba turbalasundi kasvukiiruse tendentside kōver, millel 5000-7000 radiosüsiniku aastat tagasi vōib täheldada turba väikest juurdekasvu. Andmete interpreteerimisel on viidatud lasundi kasvukiiruse ja Balti mere veetaseme eustaatiliste muutuste sōltuvusele kliimast. Nigula raba turbalasundi väikese juurdekasvu periood ennetab mõnevõrra Litoriina-mere eustaatilist veepinna tõusu. On järeldatud, et atlantilisel kliimaperioodil võis Edela-Eestis olla soe ja suhteliselt kontinentaalne kliima.

\section{K. ORGLA}

\section{CHARACTERIZATION OF ACCUMULATION SPEED TENDENCIES OF PEAT DEPOSITS THROUGH POLYNOMIAL APPROXIMATION IN NIGULA BOG}

It is suggested that a method of polynomial approximation may be used for the characterization of the speed tendencies of peat accumulation if we have a vertical series of radiocarbon datings. As a result of processing, we have obtained the curve of speed tendencies of peat accumulation in Nigula Bog. A low increment of peat deposits was stated to have occurred $5000-7000$ radiocarbon years ago. The interpretation bases on the common dependence of peat accumulation and the eustatic alterations of the Baltic Sea upon the climate. In the case of Nigula, the period of low peat accumulation increment somewhat anticipates the eustatic rise of the Littorina Sea level. A conclusion is made that South-West Estonia may have experienced a warm and relatively continental climate during the Atlantic period. 